\title{
RESEARCH OF THE PHENOMENON OF VIOLENCE AND BULLYING IN SCHOOL
}

\author{
Assoc.prof. PhD. MONICA ANGELA BARA, \\ "1 Decembrie 1918" University of Alba Iulia, Romania
}

\begin{abstract}
Violence and school bullying are just some of the manifestations of daily violence. More and more attention is being paid to violence and school bullying, facilitating public interest in youth violence, including violence and school bullying. The whole of society has become sensitive to violence and bullying in the school environment, abandoning the idea that school unity is an isolated space, unaffected by the difficulties faced by today's society.
\end{abstract}

Keywords: violence; bullying; pupils; school;

In the school unit we encounter different forms of violence, and the causes of this behavior can be multiple. Some children adopt violent behavior in their relationships with colleagues, friends, teachers, and parents. In turn, in some institutions, some teachers use the power, expressed by violence against students.

All these are just some forms of violence and bullying where we need to find a solution to provide schools with a beneficial climate and to control interpersonal violence.

In Romania, many governmental and non-governmental organizations try to tackle the increasingly common violence in all social environments. Once awareness of school violence, youth violence, and violence against children / young people, this phenomenon tends to grow like a snowball.

Violence is defined as "the ensemble of hostile conduct that can manifest in a conscious, unconscious, phantasmagoric plane, for the purpose of destroying, degrading, constraining, denying or humiliating an object invested with meaning, behaviors that are perceived as such and not provoked by it. Aggressiveness is characteristic of inter-human relations, its register of manifestations stretching to passive attitude of indifference, refusal of help, irony, teasing, to threatening attitudes and acts of violence itself " (Gorgos, C., 1985, pp. 110-112).

The most relevant definition of school violence, the most complete and meaningful for this work is the definition given by the Institute of Educational Sciences of Bucharest and UNICEF: "violence in school is any form of manifestation of behaviors such as: inappropriate or offensive expression, such as be nicknamed, teasing, ironing, imitation, threatening, harassing, crushing, pushing, hitting, injuring; conduct falling under the law; offense to the status or authority of the teaching staff; inadequate school behavior: late hours, leaving the class at school, smoking at school, or any other behavior that is inconsistent with the school regulations in force " (Jigau, M.; Liiceanu, A.; Preoteasă, L., 2006, p. 21).

School violence is often non-lethal but can cause serious harm to the person's development (Sălăvăstru, D. 2003; pag.72) identifies two types of violence in the school environment:

- objective violence that is criminal (crimes and offenses) and on which frontal intervention can occur; 
- subjective violence, which is subtler, attitude and affecting the school climate. Included here are contempt, humiliation, defiance, lack of politeness, absences from classes.

School violence is often associated with poor urban areas, with peaks, where poverty is exaggerated. Therefore, when it comes to violence in school, the external factors of the school are considered as sources: the family environment, the social environment. (Boncu, S., Neculau, A., 1998, pp. 67-70)

The social environment contains many sources of influence that can induce, stimulate and sustain school violence: the economic situation, the weakness of social control mechanisms, social inequalities, the moral values crisis, the media, malfunctions at the level of the factors responsible for youth education, cooperation of institutions involved in education. For former communist countries, the increase in violence in general, not just school violence, is attributable to a set of factors such as: media liberalization, lack of democratic exercise, increased general freedom of movement, weakening state authority and institutions committed to compliance law, access to means of aggression (Rădulescu, S. M, 1991, pag.29).

Bullying is a repeated behavioral act directed at a person's physical or mental rearing. It is also characterized by the behavior of a person who seeks to gain supremacy over others. This form of violence is most easily seen in children's groups. School is the environment where power struggles take place most often. Who is the most feared of the class, which is "dangerous gang"? Those who deal with such behaviors usually hurt others, shame them, offend them, and make different nicknames.

In school units, it increases, from day to day, a phenomenon that promotes violent behavior among children, also known as bullying. According to a study "Save the Children" in 2016, in the Romanian schools, 3 out of 10 children are threatened with co- laws. (http://salvaticopiii.ro/upload/ p000600010001_Salvati\%20Copiii_Raport \%20bullying.pdf)

Also, the Save The Children Foundation study shows that one in four children was humiliated in front of their colleagues.

Research into the phenomenon of violence and bullying.

The research aims to study the phenomena of violence and bullying in school, to give students the chance to develop their personality in a normal environment and to acquire quality education.

Violence and bullying in school include any form of behavior such as: verbal and psychological violence (nicknames, teasing, threats, harassment); physical violence; other types of deviant behavior in relation to school.

\section{The research objectives are:}

O1. Evaluating the phenomenon of violence and bullying at a high school in a small town.

O2. Identifying the causes of violence and bullying in school

O3. Identifying situations of violence and school bullying.

Hypothesis 1: Students born and raised in a violent environment also develop a bullying and violence behavior.

Hypothesis 2: The more attention, concern and concern of family members is, the higher the level of violence and bullying in the school environment will be higher;

Hypothesis 3: The lower the level of intellectual development, the higher the level of violence and bullying in the school environment;

A sociological survey based on a questionnaire was used to collect the necessary information. Questionnaire survey - this method was used to highlight the students' outlook on this phenomenon.

The questionnaire was addressed to pupils and watched: types of violence manifestations, venue and actors involved, intensity (frequency), forms of violence 
(verbal, psychological, psychic).

Limits of Investigation. Due to the low number of people surveyed, the research was purely exploratory.

By asking "What do you think are the most common causes of violent behavior among students?", We discover the most common causes of aggressive behavior in school.
We continue to assess the extent to which students believe the family has influenced their violent / aggressive behavior. Thus, the data obtained at the question "How much do you think the family influences the development of aggressive behavior in young people?"

We note that a large part $(57.8 \%)$ of the respondents appreciate that their family

Table no. 1

\begin{tabular}{|c|c|c|}
\hline Answer options & Nr. & Percent \\
\hline a. to envy & 12 & $20 \%$ \\
\hline b. age-specific territoriality & 3 & $5 \%$ \\
\hline c. lack of education, culture & 9 & $15 \%$ \\
\hline $\begin{array}{l}\text { d. television and movies that present and incite } \\
\text { violence }\end{array}$ & 6 & $10 \%$ \\
\hline e. lack of parental love & 3 & $5 \%$ \\
\hline f. aggression, innate nervousness & 5 & $8 \%$ \\
\hline g. the desire to be the focus of attention & 7 & $12 \%$ \\
\hline $\begin{array}{l}\text { h. various personal frustrations (loneliness, lack of } \\
\text { friends, material deprivation) }\end{array}$ & 10 & $17 \%$ \\
\hline i. drinking alcohol or drugs & - & $0 \%$ \\
\hline $\begin{array}{l}\text { j. the bullying and aggression they face in the } \\
\text { family }\end{array}$ & 5 & $8 \%$ \\
\hline
\end{tabular}

Of the total sample, 10 students, with a percentage of $17 \%$, believe that the most common form of violence is envy. 9 students, representing $15 \%$, are of the opinion that the lack of education and culture also influence this unfavorable behavior. Others, 7 percent, 12 percent, believe that the desire to be the focus of attention leads to such aggressive behavior.

Likewise, television, violent programs, lead to such behavior, 6 pupils, namely $10 \%$, are of the opinion. 5 pupils are of the opinion that the arguments and aggressions they attend within the family are not healthy and irreversible, which means $8 \%$, others 5 , still $8 \%$, I think this behavior can be innate.

Other 3 pupils believe that lack of parental love can distort unhealthy and aggressive behavior, and three students believe age-specific terrible affects severely, which means $5 \%$. influenced them in the adoption of aggressive behaviors and $32.95 \%$ did not have such influence at all. We can think that family models have played the most important role in involving young people in such behaviors.

So we can consider that the family is, to an important extent, responsible for engaging young people in aggressive/ violent behaviors.

We are still interested in determining the extent to which young people believe they have mastered these values within the family.

The processing of the answers to the question "The parents taught you about values such as respect for property, that it is not good to steal, that it is not good to fight?"

Shows us the the situation presented in the table no. 2 
Table no 2

\begin{tabular}{||l|c|c|c||}
\hline & Yes & No & NS/NR \\
\hline \hline a. It is important to respect the property & $92 \%$ & $8 \%$ & $0 \%$ \\
\hline b. It's important to do good things & $80 \%$ & $15 \%$ & $5 \%$ \\
\hline c. It's important to tell the truth & $77 \%$ & $32 \%$ & $1 \%$ \\
\hline d. It is better to avoid violence & $70 \%$ & $30 \%$ & $0 \%$ \\
\hline
\end{tabular}

As shown in the table above (Table 2), most students answer that they have acquired prosocial values within the family such as respect for property $(92, \%)$, the need to do good things (80\%), respect for of truth (77\%) and the avoidance of violence $(70 \%)$. However, we note the existence of an important percentage $(30 \%)$ that states that their family has a tolerant attitude towards violence.

The question "Have you ever been remarked by teachers or colleagues about the inappropriate behavior you had?" To a group reveals the behavior adopted by students in an educational institution regardless of gender. form of violence among students, only a small number indicating physical violence. Most cases of violence to which students were witnesses or victims relate to verbal violence.

Of the 27 students who responded affirmatively to the question, "Have you ever been aggressed by a classmate?", Only 3 students specified the name of the aggressor, the others refusing to do so.

A very large number of pupils consider that the most effective measures to reduce violent behaviors in school are the drop in the mark of behavior and the fine that could be applied to the parent, but of course also the type of education (community work,

Table no. 3

\begin{tabular}{||l|c|c||}
\hline Answer options & Nr. & Percent \\
\hline \hline a. yes & 22 & $37 \%$ \\
\hline b. no & 38 & $63 \%$ \\
\hline
\end{tabular}

Out of 60 students, 22 responded "Yes", which means $37 \%$, and 38 , which means $63 \%$, answered "No".

If so, what was the inappropriate behavior?

- I spoke unanswered - 8 answers;

- I used an inappropriate language - 5 answers;

- I copied them - 4 answers;

- I used the phone in an hour - 5 answers.

All students surveyed report verbal violence or bullying as the most common school, activities additional education to explain the causes and consequences of violence).

Many students indicate a nonviolent attitude in response to a possible aggression (they do not respond to the challenges, I try to settle the conflict). There are very few manifestations of teacher violence towards students and consist of exclusive verbal violence.

Most students point to indiscipline in lessons and brazenness as the main forms of manifestation of student violence against 
teachers.

The results of this research show that the family remains the most influential socializing body, with subjects attributing patterns of behavior to its influence, although most of the young people spend most of their leisure time in the company of friends. This suggests that primary socializing in the family has the most important contribution to the formation of young people, and subsequent experiences cannot change the initial training too much. Young people are aware of having internalized a series of pro-social social values ??and norms within the family.

At the same time, the whole family is perceived as the social court that has influenced violent behavior, probably based on existing social models (social learning), and this research did not aim at collecting data to prove this.

Although they spend much of their leisure time with their friends, young people do not perceive a great influence of entourage on their involvement in violent behaviors.

Much more important in the role of committing crimes in school is the school itself through its teachers and especially by how they manage to mediate the resolution of conflicts within the class of students. So young people think teachers and school should do more to comply with school regulations. An important contribution is according to the results achieved and the prestige of the school that exerts a pressure to comply with school rules and imposes a certain behavior on students and teachers.

A small number of subjects said they were involved in violent behaviors in the school, while a larger proportion underwent various forms of harassment and violence.

Although they are less involved in violent behaviors, young people still have racist behaviors that make them vulnerable to engaging in violent behaviors.

As a conclusion we can say that the family remains the main factor influencing the behavior of young people, but also a very important role played by the school in managing pupils' problems and in establishing effective social control.

In conclusion, the answers of the questioned pupils show that the phenomenon of violence and bullying exists, but it does not reach worrying proportions. Effective measures to prevent and combat violence in schools are required, leading, if not at the removal of the whole, to at least a reduction in the number of acts of violence.

\section{Conclusions}

The present paper gave me the chance to investigate, violence and bullying in school, these problems we meet more and more often.

I turned my attention to the preadolescent / adolescent who is characterized by psychic instability, by impulsivity, presents antisocial actions, and creates many problems both in the family and at school.

Analyzing the causes that lead to behavioral deviations, we appreciated the influence of four categories of factors: individual factors, school factors, intellectual factors and non-intellectual factors. Failure to consider any of these will contribute to the diminution of educational quality and the development of deviant behaviors.

Through the applied questionnaire, I was given the opportunity to study students' behavior, the relationships between them and the teachers, the forms of violence, the impact of anger on them.

The paper highlighted the importance of counseling in preventing and combating violence and bullying in students. The results of the counseling activity are very important for the pupil, as it gives him the opportunity to get to know himself and to appreciate his true value.

The phenomenon of violence and school bullying needs to be analyzed in the context of its occurrence. School can play an important role in preventing school violence. 
And this not only in the conditions where the sources of violence and bullying are in the school environment, but also in the situation where the sources are outside the school.

\section{References}

1. Boncu, S.; Neculau, A., (1998), Deviation, tolerance and normative conflict in the conflict resolution psychology, Ed. Polirom, Iaşi.

2. Gorgos, C., (1985), Encyclopedic Dictionary of Psychiatry, vol. I, Ed. Medicală, Bucharest.

3. Jigau, M.; Liiceanu,A.; Preoteasă, L., (2006), School violence, Ed. Alpha. Bucharest.

4. Jinga, Mihaela; Liiceannu, Aurora; Preoteasa, Liliana (coord.), (2005), Violence in school, Ed. Polirom, Iaşi.

5. Krug, E.G., (2002), World report on violence and health, World Health Organization, Geneva.

6. Neculau, A.(coord), (2003), Violence in the school environment, Ed. Polirom, Iaşi.

7. Rădulescu, S. M., (1991), Anomie, deviance and social pathology, Ed. Hyperion, Bucharest.

8. Sălăvăstru, Doina, (2003), Violence in the school environment, Ed. Polirom, Iaşi.

9. (http://salvaticopiii.ro/upload/p000600010001_Salvati\%20Copiii_Raport\%20bullying.pdf) 